\title{
Geeks, Social Imaginaries, and Recursive Publics
}

\author{
Christopher Kelty \\ Rice University
}

Openness and scalability, modularity and trust, transparency and security; these are some keywords emerging from contemporary debates about the structure and future of the Internet among engineers, entrepreneurs, and other individuals intimately involved with the programming and design of technical infrastructures. Such terms of debate may not be familiar to anthropologists and other cultural commentators who more regularly focus on the workings of gender, race, and identity or analyze structures of power, sovereignty, and governance. However, they are no less terms of political contest for being embedded in technical practice. This nexus of technology and politics is where the fieldwork described in this article took place, focusing on a distinct social group whose defining characteristic is recursive in nature: a group constituted by a shared, profound concern for the technical and legal conditions of possibility for their own association. I call this mode of association a "recursive public"; the people who participate in it will be referred to as "geeks"; and the Internet is the condition of their association. ${ }^{1}$

One way to bridge the apparent gap between the arcana of the technical and legal structure of the Internet and a critical anthropological vocabulary is to understand the Internet as a contest. It is neither stable nor single but is constantly being rewritten and recompiled according to diverse, partially shared, shifting, and incomplete objectives, not only by individuals but also by corporations, governments, and universities. The ethnographic analysis below concerns a specific example of this constant and contested rewriting in a set of exchanges among geeks occurring in the spring and summer of 2000. These exchanges concerned Napster and attempts by corporations and the Recording Industry Association of America (RIAA) to legally control and transform the on-line music world and parts of the Internet. This example is selected from fieldwork among geeks conducted over several years in Boston (1996-99), Berlin (1999-2001), and Bangalore (2000-01). The specific case presented here is taken from a mailing list called Silk List moderated by one of my chief interlocutors in Bangalore, Udhay Shankar N.

CULTURAL ANTHROPOLOGY, Vol. 20, Issue 2, pp. 185-214, ISSN 0886-7356, electronic ISSN 1548-1360.

(C) 2005 by the American Anthropological Association. All rights reserved. Please direct all requests for permission to photocopy or reproduce article content through the University of California Press's Rights and Permissions website, www.ucpress.edu/journals/rights.htm. 
The Internet as a contest is analyzed here using the notion of a recursive public, a particular form of social imaginary through which this group imagines in common the means of their own association, the material forms this imagination takes, and what place it has in the contemporary development of the Internet. ${ }^{2}$ Charles Taylor, Michael Warner, and Jurgen Habermas, each in his own way, have suggested that the public, or public sphere, can be thought of as one example of a social imaginary. Social imaginaries are neither strictly ideas nor strictly institutions but "ways in which people imagine their social existence, how they fit together with others, how things go on between them and their fellows, the expectations that are normally met, and the deeper normative notions and images that underlie these expectations." Such imaginaries are not static but are "schematized in the dense sphere of common practice" and subject to something like a dialectical transformation (Taylor 2002:106). Geeks spend a lot of time making, coding, building, compiling, patching, redistributing software code and networking technologies (their dense sphere of common practice), and talking it up in a manner that is often facilely dismissed as "hype." The conceptual tool of a "social imaginary" is important for my analysis because it permits a description of how geeks imagine their social existence through these technical practices as much as through discursive argument. It is particularly appropriate in this case because the practice of writing software is precariously situated between verbal argument and material practice; indeed, software creation itself represents a certain immanent critique of the very distinction between speech and practice and thus requires a more careful ethnographic analysis.

The notion of a recursive public as a social imaginary specific to the Internet draws together technical practices of coding and designing with social and philosophical concepts of publics to highlight specific contemporary ideas of social or moral order that just as often take the form of argument-by-technology as they take the form of deliberative spoken or written discussion. When geeks argue, they argue about rights and reasons, but they also argue about the Internet as the technical structure and legal rules that allow them to argue in the first place. Furthermore, not only do they argue about these structures and rules, but they consider sacred the right to change these rules by rewriting and reimplementing the core protocols (the "rules") and core software that give the Internet its structure; they also consider it essential that individuals and groups in society have the right to reimplement privately ordered legal regimes to achieve these ends. ${ }^{3}$ These arguments are neither idle nor do they represent how the Internet "really is"- they are imaginaries of what gives the Internet its present order or how it should be ordered in the future.

Thus, techniques and design principles that are used to create software or to implement networking protocols cannot be distinguished from ideas or principles of social and moral order for these informants. Openness, which will loom large in the example below, is a practice and a concept on which recursiveness depends: If one cannot access and see the software and protocols, if they are not open, this 
particular public cannot exist. ${ }^{4}$ This commitment to openness bears some similarity to J. S. Mill's version of a liberal polity in which all ideas are allowed to circulate because it strengthens and highlights the best ones. For geeks, writing software and configuring networks are as essential to freedom and public participation as is speaking to a public about such activities. The right to create software is seen in a similar light as the right to state an opinion. If your opinion (software implementation) is heard, critiqued, refined and reasserted - just as Mill proposed - then the best (the truest) opinion will win out. This process will be explored here in the context of the core protocols of the Internet and the process for standardizing them in Requests for Comments (RFCs).

In this article, both argument-by-technology and discursive argument are followed to trace how openness exists simultaneously in both forms: first, as the rhetoric and ideas espoused by individuals who work on, care about, have responsibility for, or otherwise see themselves as involved in the Internet; and second, as the real technical and legal structure that the Internet may take at a particular moment in time. This article differs from existing research in that it uses this example and these informants primarily as a means for carrying out an ethnography not of geeks but of the Internet itself. ${ }^{5}$

Geeks are good informants because they provide a necessary complement to studies of people "on" the Internet, especially in their unbending focus on the production of the very means of communication and association. Geeks are described in detail here not to characterize them as a culture but because they provide a particularly rich route to understanding the new technical and legal forms of affiliation and practice that humans and their devices engage in-that is, this analysis includes in social life the technical relations of nonhuman as well as human actors. ${ }^{6}$ These technical relations include not only hardware, but software, networking protocols, and legal tools such as copyright licenses. The primary theoretical influences come from science studies, in which the concept of "network" long precedes the scholarly interest in the Internet (Latour 1999a).

This article therefore treats the Internet not only as a network in this sciencestudies-derived sense- a technical and social assemblage whose form consists in the constantly changing relations amongst humans and nonhumans (see Law 2002 for a similar approach)—but also as a real network whose particular technical and legal forms can be shown to have an impact on how these abstract relations are constituted or transformed. In this sense, this approach is a cultural analysis insofar as it includes assessments of how and why particular configurations of software, hardware, and legal regulation are valued over others, and how these values are discussed and acted on in practical settings. It is a thick description of the process through which one set of geeks comes to imagine in common the technical and legal configuration of the very medium that makes it possible for them to associate with each other. The concept of "recursive publics" is therefore meant to comprehend something more tangible than ideology and less absolute than a technocracy. ${ }^{7}$ 
The motivation to use geeks as informants and thereby extend the theoretical concepts of publics and social imaginaries to analysis of technical discourse speaks to the challenge of understanding new modes of political change specific to highly technical societies. How are shared ideas filtered through particular technical and legal structures that both constrain and make possible new forms of affiliation and challenge existing understandings of political life? How are these technical and legal structures the products as well as the targets of groups who imagine in common a particular mode of association and political speech?

The recent controversies over electronic voting machines in the United States, Ireland, and India show us what is at stake in shifting the focus to the technical and legal configuration of the Internet. In the United States, almost all available electronic voting machines are run on proprietary software (managed and created by particular corporations). The source code together with the government certification procedures for those machines and their software are confidential and inaccessible to anyone but the private voting machine companies themselves. In 2004, the widespread, large-scale purchase of these machines by state and county governments split observers into two camps: on the one hand, many argued that the electronic voting machine solved particular problems, such as increasing access and accuracy, especially for handicapped, blind, or deaf voters. On the other hand, many argued that the machines were insecure and the makers of these machines were unaccountable because of the lack of transparency in how they worked. Even groups formerly united around social issues of voting access, such as the nonpartisan League of Women Voters, have been riven by controversies over these new technologies. ${ }^{8}$ Academic computer scientists, not usually known for their political activism, came out to argue (remarkably!) for more paper and less trust in computers while political scientists, poll workers, and disability activists argued that the risks of what they saw as correctable technical shortcomings were worth the gains in access and equality.

The stakes of this controversy go right to the heart of politics in highly technical societies because they concern the very issue of who controls and who builds the means of political participation. Computer scientists arguing for more openness are essentially saying that technologies can, in fact, relegislate the structure of democracy; indeed they lend specificity to the very idea of a technical society by redefining civic responsibility as a call to engage in technical criticism of rapidly changing means of representation. Of course, their position may itself be criticized in view of their own interests - and one may doubt the earnest appeals to the public interest-but the aim in this article is to track argument-by-technology for what it reveals about critique within contests about control over the means of discourse and about the shifting line between speech and technology. In what follows, I analyze the arguments that geeks offer about their technical practice in relation to the concepts of public sphere and social imaginaries by exploring a particular set of discussions about the technical and legal constitution of the Internet. Analysis of the arguments of informants in relation to concepts of publics and social 
imaginaries as they relate to the Internet make use of a particular example to illustrate how these arguments are conducted and what they imply. In the conclusion, I assess how the notion of social imaginaries can be extended in light of these technical and legal issues.

\section{Geeks I Have Known}

On the day I arrived in Bangalore, after a 3 a.m. struggle to rouse the hotel manager to let me in, a four-hour half sleep, and a long wander around the neighborhood to look for a mobile phone card, Udhay Shankar N showed up to take me out on the town. I had met Udhay in 1999 through a newsletter, distributed via e-mail, called “Tasty Bits from the Technology Front." He invited me to visit and promised to introduce me to everyone he knew. I needed a mobile phone because Udhay could not imagine what I would do without one. Whenever I called him, he would answer by saying, "Where are you?" which was the perfect tagline for my own bewildering path that led from Boston to Berlin to Bombay (Mumbai) to Bangalore via a hundred mailing lists, meetings, e-mails, and lounges, on-line and off. How could I even know "where I was" without a mobile phone by which to be so addressed? Fortunately, my German Nokia phone allowed me the option of a GSM card by Spice Networks (an Indian telecom operator based in Punjab and operating in Karnataka) that gave me the very memorable phone number "spice-chili" and a few hundred minutes to work with.

Udhay described himself as a "random networker" and was at the time working for an Internet start-up company. Despite the hype, this company was a real rarity being one of the few in the country modeled on the American venture-funded "test-fast, fail-fast," give-your-employees-bean-bags-and-espresso-machines style of start-up. He was not really a programmer or a designer, despite his extensive knowledge of software, devices, operating systems, and so on. He also was not a businessman, but instead described himself as the guy who "translates between the suits and the techs."

We piled into Udhay's car and drove fast through the streets of Bangalore blaring heavy metal music. He was taking me to a bar that he insisted was a necessary stop for any new arrival in India. Given Bangalore's reputation as a Westernized city, its high population of youngsters, its proximity to the highprofile Indian Institute of Science, and its generally more permissive attitude, the city boasts hundreds of pubs. Some would not be out of place in New York, outfitted with lavish decoration and outrageously priced drinks; others are kitschy (the NASA pub, the London Underground Pub), and still others are predictable (the Irish bar). Almost all of my discussions took place in these bars, as they were a more likely meeting place than people's homes or offices. Udhay insisted that the bar he was taking me to was a hangout for the tech industry. It was called Purple Haze and was decorated with posters of Jimmy Hendrix, Black Sabbath, Jim Morrison (Udhay: "I hate that band"), Led Zeppelin, and a somewhat out of 
place Frank Zappa (Udhay: "One of my political and musical heroes"). The bar was smoky, dark, purple, and filled with men between 18 and 30. All of them, it appeared, were singing along with the music, which was almost without exception heavy metal (to my shame, it was only the works by Metallica that I could name, much less sing along with).

I engaged in some stilted conversation with Udhay and his cousin Kirti about the difference between Karnatic music and rock and roll, which seemed to boil down to the following: Karnatic music decreases metabolism and heart rate leading to a relaxed state of mind, rock music does the opposite. Given my professed aim of focusing on the Internet and questions of openness, I had already decided not to pay attention to this talk of music. In retrospect, this was a grave methodological error. Over the course of the evening and the following days, Udhay introduced me to a range of people he either knew or worked with in some capacity. It was what he had promised to do, and he delivered. Almost all of them, it appeared, sincerely loved heavy metal music. ${ }^{9}$

The people I was introduced to, it turned out, had much in common. Most of them worked in the IT industry, and because Udhay is someone who, as he puts it "collects interesting people," they tended to be more cosmopolitan and were more discerning in their job choices than most of the wide-eyed and highly paid youngsters at work in Bangalore's IT field. There were at least two lawyers, a handful of people who worked in middle management, and a bunch of people who in some form or another worked at technical pursuits. It was hard to specify exactly what they did, because one of the games they liked to play is to invent new job titles. I began to collect their business cards: coder, hacker, Software Architect, Software Developer, Software Engineer, Computer Engineer, Systems Administrator (sysadmin), Software Consultant, Research Scientist, Security Architect, Technology Consultant, Systems Researcher, Information Architect, Information Engineer, Market Strategist, Virtual Community Engineer, Software Design Artist, Principal Architect. Those were the most common, the straightest. Others were more creative: Lead Indentured Slave, Renegade Technologist, Hackematician, Unhinged Eccentric, Rogue Scholar, Bit Heeler, Free-Lance Open Source Fundamentalist, Stunt Programmer, Code Double, Understudy, Netscapee, Netscapegoat, Head Ompalumpa, Pixel Cowboy, Expert, Email Sturmbahnführer and Lower Middle Class Sysadmin, Rocket Scientist, Lord High Master of all things Electrical and Fluid, Master of Kode-Fu, Principle Architect, and my personal favorite, for the (Latin) American sysadmin: Senõr Programmer.

The fact that some of them could describe themselves as "Netscapees" or in one particular case "Lead indentured slave" at Netscape, pointed to their experience of the grim realities of immigration, migration, and labor markets. Many of them had done stints in either the United States or England, some had been body shopped, others had been body shoppers at one time or another. ${ }^{10}$ They were coming from or headed for Ireland, Singapore, Hong Kong, Seoul, and Sydney. Just prior to my 
arrival in Bangalore, Germany and India had tried to broker a "red-green card" (called so because it was sponsored by both the Socialist and Green parties). In February 2000, Chancellor Schroeder announced his desire to bring in 30,000 highly trained Indian software experts to be what were openly referred to as "hightech Gastarbeiters" (mirroring the long-standing practice of allowing Turks to immigrate on a "guest" basis to work in the building trade but denying them most rights of citizenship). ${ }^{11}$ This plan created tremendous conflict about immigration into Germany, and ultimately it failed miserably both economically and culturally (the Germans accused each other of racism and cultural isolation while the Indians tended to project their fantasies of Nazis and beer halls onto the country; for most Indians, the cost of relocation and the hardship of learning a new language was not worth the compensation Germany was offering). In the end, almost no Indian IT workers took advantage of the program, but much to the horror of some Germans, many Eastern Europeans did. At the time, many of the discussions of the German proposal centered on religion, especially the ignorance of most Germans about India's substantial Muslim population. Among the geeks that Udhay introduced me to, there were Muslims, Hindus, Jains, Jews, Parsis, and Christians, but most of them considered themselves more secular and scientific than religious. The only thing that seemed to be more or less invariable was that they were almost 100 percent male and (as I have noted above) they all loved heavy metal music. ${ }^{12}$

While I was in Bangalore, and long after I left, I stayed in touch with this group via e-mail (but also through various European conferences, temporary media labs, meetings, or through friends). One particularly successful point of contact was a mailing list run by Udhay called Silk List, an irregular, unmoderated list devoted to "intelligent conversation." From an anthropological standpoint, the kind of material collected in this list (more than 10,000 messages as of 2003) is a treasure. Long meandering conversations about Indian politics, religion, economics, and history erupt regularly and usually result in vigorous disagreements and occasional flashes of startling insight. Although the topics on Silk List ranged from science fiction and movie reviews to discussions on Kashmir, Harry Potter, transhumanism, or Napster, the function of the list was not so much to provide a forum for the subject matter at hand (this could be had in many other places) but offered instead a site of connection for loosely affiliated groups sharing particular concerns about technology, society, and the Internet that were neither explicit nor determined in each case by the same cultural or social location.

Udhay started Silk List in 1997 with Bharath Chari and Ram Sundaram, and the recipients have included a large number of people around the world, some of them very well-known: programmers, lawyers, a Bombay advertising executive, science fiction authors, entrepreneurs, at least two transhumanists, one (diagnosed) schizophrenic, and myself. Active participants usually number about 10-15, whereas many more may lurk in the background. Much of the discussion references a wider world of Internet and technology-related politics and activities with which it is assumed the recipients are more or less familiar. 
The relationship between the network of people in Bangalore and their connection to a worldwide community on the Internet is a fascinating story of the power of heterogeneously connected networks and media. Udhay explained that in the early 1990s he first participated in and then taught himself to configure and run a modem-based networking system known as a Bulletin Board Service (BBS) in Bangalore. Somehow, in 1994, he heard about a book by Howard Rheingold called The Virtual Community, which was his first introduction to the Internet. A couple of years later when he finally had access to the Internet, he immediately e-mailed John Perry Barlow, whose work he knew from Wired magazine, to ask for Howard Rheingold's e-mail address so that he might connect up with him. Rheingold and Barlow exist, in some ways, at the center of a certain kind of geek world - Rheingold's books are widely read popular accounts of the social and community aspects of new technologies that have had considerable impact internationally. Barlow helped found the Electronic Frontier Foundation and is responsible for popularizing the phrase "information wants to be free" (Barlow 1994). Both men had a profound influence on Udhay and ultimately provided him with the ideas central to running an on-line community. A series of other connections of similar sorts, some personal, some precipitated out of other media and other channels, some entirely random, are what make up the membership of Silk List.

Like many similar communities of "digerati" during and after the dot.com boom, Silk List constituted itself more or less organically around people who "got it" - that is, people who claimed to understand the Internet, its transformative potential, and who had the technical skills to participate in its expansion. Silk List was not the only list of its kind. Others such as the Tasty Bits newsletter, the FoRK (Friends of Rohit Khare) mailing list (both based in Boston), or the Nettime and Syndicate mailing lists (both based in the Netherlands) ostensibly had different reasons for their existence but often had many of the same subscribers and overlapping communities of geeks. Subscription was open to anyone, and occasionally, someone would stumble on the list and join in, but most were either invited by members or friends of friends, or else they were connected by virtue of cross-posting from any number of other mailing lists to which members were subscribed.

To be precise, these particular geeks are not representative of everyone who cares about or works on the Internet, and they do not stand in for any one group such as hackers, coders, engineers, activists, computer nerds, cypherpunks, bloggers, or sysadmins (although there is at least one of each in the group). ${ }^{13}$ Although the term geek bears much weight in defining the object of study in this case, this is not an ethnography of geeks. ${ }^{14}$ Only one significant quality is shared by all of the geeks represented here: they are a public constituted through a shared sense of concern for the technical and legal conditions of possibility of their own association. The fact that the participants in Silk List have been brought together by mailing lists, e-mail, BBSs, books, modems, air travel, academia, and cross-posting in ways that were not possible before the Internet is something that is at the core of their 
own often articulate reasoning about why they associate with each other. They understand, and in many cases helped to build, the means of their association (e.g., the parts of the Internet and the networks and mailing lists through which they are enabled to interact), and they continue to mobilize its historically open structure to influence the development of the technical and legal structure of the Internet as a whole. The members of Silk List are therefore a very specific set of informants for understanding the functioning of immanent technical critique in contemporary contests over the Internet and its future.

\section{The Summer of Napster}

A message was posted to Silk List on July 27, 2000, by Eugen Leitl with the subject line "Prelude to the Singularity." The author of the message, Jeff Bone (not then a member of Silk List), called it an "op-ed piece" and posted it initially to the FoRK mailing list as a response to the RIAA's actions against Napster. The RIAA had just succeeded in getting U.S. district judge Marilyn Hall Patel, 9th Circuit Court of Appeals, to issue an injunction to Napster to stop downloads of copyrighted music and Bone's commentary addressed this development as follows:

Popular folklore has it that the Internet was designed with decentralized routing protocols in order to withstand a nuclear attack. That is, the Internet "senses damage" and "routes around it." It has been said that, on the "Net, censorship is perceived as damage and is subsequently routed around. The RIAA, in a sense, has cast itself in a censor's role. Consequently, the music industry will be perceived as damage - and it will be routed around. There is no doubt that this will happen, and that technology will evolve more quickly than businesses and social institutions can; there are numerous highlyvisible projects already underway that attempt to create technology that is invulnerable to legal challenges of various kinds. Julian Morrison, the originator of a project (called Fling) to build a fully anonymous / untraceable suite of network protocols, expresses this particularly eloquently. ${ }^{15}$

As I have already ruefully related, my failure to appreciate my informants' obsession with heavy metal ill-equipped me to understand how important the attack on Napster would prove not just for American youth but also for rock and roll fans worldwide. The Napster shutdown touched music fans and geeks alike, where it hurt, nor did it really help the record labels who perpetrated it. ${ }^{16}$ For many geeks, Napster represented the Internet in miniature - an innovation that both demonstrated something on a scope and scale never seen before and that also connected people according to what they most cared about.

The passage quoted above nicely demonstrates a series of points that help clarify how geeks understand the relationship of law and technology and why they might be called a "recursive public." First, the title "Prelude to the Singularity" is a reference to an article by Vernor Vinge about the notion of a "singularity" - a point in history when the speed of technology change overcomes the ability of humans to adapt to it, understand it, or more importantly, to stop it (Vinge 1993). It is a frequent point of reference for geeks on the Internet who are generally sympathetic 
to the idea of autonomous technical progress and more specifically to the goals of transhumanists or extropians. This notion of singularity is not always referred to by geeks as merely science fiction but rather as a law of sorts, such as Moore's law, Metcalf's law, and many other so-called laws that make up the social theories of Internet geeks. ${ }^{17}$

The idea of "singularity" developed in Vinge's work references a set of more or less articulated stories about history, evolutionary theory, economic theory, and experience with the progress and innovation of modern technology. Transhumanists and their sympathizers generally believe that technological progress is autonomous and that no central authority can direct it (an insight that they think they get from evolutionary biology); they also tend to be very strong believers in self-interest and suspicious of any claimants who think otherwise. Jeff Bone's article "Prelude to the Singularity" is, therefore, speaking to an audience that is accustomed to hearing about the inevitability of technical progress and the impossibility of legal maneuvering to change it. Of course, not all geeks believe this, and in fact, such talk often results in long drawn out flame fests, recriminations, and accusations of stupidity, as was the case with Bone's e-mail on Silk List, and several other postings that summer.

A second point worth emphasizing is the recognition in Bone's article that the locus of power (especially concerning censorship and repression) does not primarily reside with the government or the church but comes instead from the private sector, in this case the coalition of corporations represented by the RIAA. Whether the blocking of file sharing can legitimately be called censorship was not addressed by Mr. Bone, and many of the Silk List respondents found such an accusation of censorship untenable. However, in light of more recent events, it has become clear that the RIAA and the MPAA (Motion Picture Association of America) have been given considerably more police authority than even many federal agencies - especially concerning the policing of networks themselves (an issue that, in its technical abstruseness, is rarely mentioned in the mainstream mass media). Both organizations have sought not only to prosecute file sharers but have been granted rights to obtain information from Internet Service Providers about customer activities and have consistently sought the right to secretly hack into and disable or destroy private computers suspected of illegal activity. Even if these issues may not be defined as censorship per se, they are nonetheless fine examples of the issues that most geeks get exercised about-that is, the use of legal means by a few to suppress or transform technologies in wide use. ${ }^{18}$

Third, although this message was written as an "op-ed" piece on the issues surrounding the RIAA and Napster, it was not published anywhere as such and it was not widely cited or linked to (as of this writing). However, it did have at least one day of being a topic for heated discussion topic on three other mailing lists, including Silk List. The fact that it was written and circulated as a potential op-ed piece, however, brings up an interesting methodological point: this material rests somewhere between private conversation and published opinion. No editor 
made a decision to "publish" this message. However, as with any print publication, it is potentially accessible by anyone. In terms of addressing or being addressed in a public sphere, the difference is in this radical openness. On the one hand, constraints on who speaks in a public sphere (such as the power of printers and publishers, the requirements of licensing, or issues of cost and accessibility) are much looser here than in any previous era-it gives a previously unknown Jeff Bone the power to dash off a manifesto without so much as a second thought. On the other hand, the ease of distribution belies the difficulty of being heard-the massive number of other Jeff Bones makes the issue of being heard much more difficult.

Fourth, the importance of the Internet protocols is where the contestation over the control of the means of address is most clearly visible. Jeff Bone's post begins with a series of statements that are part of the common repertoire of "technical stories and images" among geeks. He begins by making reference to the "folklore" of the Internet, in which routing protocols are commonly believed to have been created to withstand a nuclear attack. In calling it folklore, the author suggests that this widely held assumption may or may not be true, but he also proceeds to confuse it with a more recent bit of folklore that assumes "the Internet treats censorship as damage and routes around it."19 This quote from the 1990s is attributed to Electronic Frontier Foundation's founder and "cyber-libertarian" John Gilmore (see www.eff.org). Both bits of folklore are widely circulated and cited; they encapsulate one of the core intellectual ideas about the architecture of the Internetthat is, its open and distributed connectivity. In the early 1990s, it was part of a very vibrant libertarian dogma asserting that the Internet simply could not be governed by any land-based sovereign and that it was fundamentally a place of liberty and freedom. This was the central message of people such as John Perry Barlow, John Gilmore, Howard Rheingold, Esther Dyson, and a host of others who populated both the pre-1993 Internet (before the World Wide Web became widely available) and the pages of magazines such as Wired and Mondo 2000-and this was the same group of people whose ideas were visible and meaningful to Udhay Shankar and his friends in India even prior to the existence of Internet access there.

For Jeff Bone (and a great many geeks), the folkloric notion that "the net treats censorship as damage" is a very powerful one: it suggests that censorship is impossible because there is no central point of control. A related and oft-cited sentiment is that "trying to take something off of the Internet is like trying to take pee out of a pool." This is often perceived as a significant virtue of the Internet, not as a drawback. It ensures that censorship cannot happen, technically speaking, so long as its protocols and software remain open. Furthermore, it ensures that all attempts to regulate the Internet will also fail (e.g., a related sentiment is expressed as: "the Internet treats Congress as damage and routes around it").

However, this view of the unregulatable nature of the Internet has been roundly criticized by other (often left-leaning) geeks and, most prominently, by 
the superstar lawyer cum geek Lawrence Lessig, who is otherwise often in sympathy with geek culture. Lessig (1999) suggests that just because the Internet has a particular structure, this does not mean that it must always be that way. He does not suggest that the law is more effective than geeks give it credit for but that technical configurations function like law and are therefore far more fragile and contingent than hitherto recognized. There is nothing inevitable-technically speaking - about its openness. So, although it may be true that no one can make the Internet "closed" by passing a law, it is also true that the Internet can become closed if the technology were to be altered for that purpose; a process that may well be nudged and guided by laws and regulations.

At some level, many geeks recognize the validity of this critique, and they often argue in detail about what distinguishes technical factors from legal or social ones. Openness on the Internet is complexly intertwined with issues of availability, price, legal restriction, usability, elegance of design, censorship, trade secrecy, and so on. Many believe that openness is a natural tendency for technology (e.g., in an often made analogy with reproductive fitness) and where laws shut things down, technologies arise to work around law. Similarly, in the case of Jeff Bone, openness means simply "invulnerable to legal attack" because "technology will evolve more quickly than businesses and social institutions can," thus making it impossible for a legal assault to close it off. However, Bone is not only referring to the fact that the Internet's novel technical configuration has few central points of control, making it difficult for a single institution to control it, he is also giving importance to the distributed, loosely connected networks of people who write software and deal regularly with the underlying protocols of the Internet (i.e., geeks). As I have been suggesting, these geeks are self-addressing and self-organizing. Although they all work for particular organizations, corporations, governments, or small businesses, they nonetheless identify with something beyond their local situation. There is no formal organization that binds them together, other than the Internet itself. Indeed, there are only a few institutions that might be said to govern the Internet — and by no means do all geeks belong to them. ${ }^{20}$

One such institution is the Internet Engineering Task Force (IETF), a longstanding association of Internet engineers who try to help disseminate some of the core standards of the Internet. Another famous bit of Internet governance folklore is attributed to IETF member David Clark: "We reject kings, presidents, and voting. We believe in rough consensus and running code." 21 If "it works," then it can be implemented; if it is implemented, it will "route around" the legal damage done by the RIAA. Suing the IETF would have little or no effect because, as they say, they reject monarchy and democracy alike. They are devoted only to maximally distributed power, and they are responsible only for setting Internet specifications (which instruct engineers on how computers should connect to each other and what information they should exchange when they do), not their implementation. ${ }^{22}$

The notion of "running code" is central to an understanding of the relationship between argument-by-technology and argument-by-talk for geeks. Very 
commonly, the response to people who spoke about the summer of Napster-and the courts' decisions regarding it—was to dismiss their complaints as mere talk. Many people suggested that if Napster were shut down, thousands more programs like it would spring up in its wake. As one mailing list participant, Ashish "Hash" Gulhati, put it:

It is precisely these totally unenforceable and mindless judicial decisions that will start to look like self-satisfied wanking when there's code out there which will make the laws worth less than the paper they're written on. When it comes to fighting this shit in a way that counts, everything that isn't code is just talk. ${ }^{23}$

Geeks tend to see technical solutions to problems as trumping all legal ritual; it is an attitude of "shut up and show me the code." Often such talk is somewhat paradoxical_-posters that insist on the importance of skipping the argument and moving directly to coding some new technology recognize the necessity of talking about doing just that. One of my Silk List colleagues, Eugen Leitl, said the following when I pointed this out:

Of course we should talk. Did my last post consist of some kickass Python code adding sore-missed functionality to Mojonation? Nope. Just more meta-level waffle about the importance of waffling less, coding more. I lack the proper mental equipment upstairs for being a good coder, hence I attempt to corrupt young impressionable innocents into contributing to the cause. Unashamedly so. So sue me. ${ }^{24}$

Despite the fact that the RIAA had actually turned to suing people, this flippancy indicated a recognition that there is a political component to coding, even if, in the end, talk disappears and only code remains. Although Eugen and others might like to adopt a rhetoric that suggests "it will just happen," in practice, none of them actually act that way. Rather, the activities of coding, writing software, or improving and diversifying the software that exists are not inevitable or automatic but have specific characteristics; they require time and "the proper mental equipment." The inevitability they refer to consists not in some fantasy of machine intelligence but a social imaginary shared by lots of people in loosely connected networks who spend all their free time building, downloading, hacking, testing, installing, patching, coding, arguing, blogging, and proselytizing.

Jeff Bone's op-ed piece, typically enthusiastic about the inevitability of new technologies, still takes time to reference one of thousands (perhaps hundreds of thousands) of projects as worthy of our attention and support-a project called "Fling," which is an attempt to rewrite the core protocols of the Internet. ${ }^{25}$ The goal of the project is to write a software implementation of these protocols with the explicit goal of making them "anonymous, untraceable, and untappable." Fling is not a corporation, a start-up, or a university research project (although some such projects are); it is only a website. ${ }^{26}$ The core protocols of the Internet are little more than documents describing how computers should interact with each other. They are standards but of an unusual kind (Kelty 1999; Schmidt and Werle 1998). 
Important to understanding why geeks think such protocols are so important and why they would consider it a political right to reimplement them is the role of the IETF and the style of standards it promulgates. For the first 20 years, Internet protocols were contained primarily in documents called "Requests for Comments" (RFCs) circulated to Internet members and managed by the IETF and later the Internet Society. These RFCs were primarily suggestions-not demands. They were essentially public domain documents and available to everyone. As David Clark's reference to "consensus and running code" (quoted above) demonstrates, the essential component of setting Internet standards is a good working implementation of the protocols. Someone must write software that behaves in the ways specified by the RFC, which is only a document, not a piece of software. Different implementations of, for example, the TCP/IP protocol or the FTP protocol depend initially on individuals, groups, and/or corporations building them into an operating system kernel or a piece of user software and subsequently depends on the existence of a large number of people using the same operating system or application. From the late 1970s to the present, that operating system has primarily been UNIX and its variants (such as Solaris, Xenix, BSD, or Linux), but almost all modern operating systems now contain implementations of the core protocols of the Internet-indeed, as do thousands of smaller devices such as mobile phones and Personal Data Assistants (PDAs) as well.

In many cases, subsequent to an implementation that has been disseminated and adopted, the RFCs have been amended to reflect these working implementations and to ordain them as standards. So the current standards are actually bootstrapped, first through a process of writing RFCs, followed by a process of creating implementations that adhere loosely to the rules in the RFC, then observing the progress of implementations (where they differ from the RFC, how many people are using this implementation, and other less obvious criteria), and then rewriting RFCs so that the process begins all over again. The fact that geeks can have a discussion via e-mail depends on the very existence of both an RFC to define the e-mail protocol and implementations of software to send the e-mails. Thus, the public sphere of geeks is recursive precisely because of its ability to discuss (via e-mail) and potentially reimplement (in a new software program) the protocols described in the RFCs that are devoted to e-mail transfer (or, for that matter, any other protocol such as those for file sharing or for the DNS) on the Internet. ${ }^{27}$ In the past, other than having access to a computer and the Internet, the primary criterion for participation in this process was, simply, that one was a geek who cared about such things. No national, corporate, organizational, professional, or other systems of inclusion or credentialing were used to exclude people.

Although it is rarely so cut and dried in practice, there is always extensive talk about how to implement new software, how to get money to support a project, how to publicize it, how to recruit more people, who to recruit, as well as a host of arguments justifying or critiquing both actual and proposed implementations. The focus on implementation is not intended to shut down discussion of other 
concerns - indeed, it often opens the door for many others to participate without having to be coders. Eugene Leitl's reference (cited above) to corrupting young minds means simply that he seeks to convert them to the cause of radical openness. The very reason for pursuing these technical changes is to continuously ensure the future possibility for continued association, dissent, and technical creativity. In the end, geeks are proselytes; they would much prefer that the rest of the world join them in their social imaginary than that they be forced to live under conditions they view as inaccessible to critique. In this sense, geeks struggle to keep the recursive public sphere of the Internet radically open - both to participation and to critiqueeven though the conditions for entering into this sphere require participants to be geeks (i.e., to know what they are talking about).

\section{Social Imaginaries after the Internet}

Charles Taylor (2004), building on Habermas (1989) and Warner (1990), suggests that the social imaginary of the public sphere that emerged in the 18th century was created through a set of transformed practices of communication and association that reflected a particular kind of moral order. Contrary to the experience of bodies coming together into a common space (Taylor calls them "topical spaces," in which conversation, ritual, and assembly take place), the crucial component was that the public sphere:

transcends such topical spaces. We might say that it knits a plurality of spaces into one larger space of non-assembly. The same public discussion is deemed to pass through our debate today, and someone else's earnest conversation tomorrow, and the newspaper interview Thursday and so on.... The public sphere that emerges in the eighteenth century is a meta-topical common space. [Taylor 2004:86]

Michael Warner's (2002a, 2002b) contribution to the theorization of social imaginaries adds crucial specificity to this idea. Warner offers a specification of the practical nature of today's publics by distinguishing the imagination of the public from particular publics (and counterpublics). Warner suggests that the idea of a social totality indicated by the public (i.e., a social imaginary) is quite different from a specific instantiation (a public). Particular publics happen all the time through a process of discursive address and performed attention. A particular public is not itself a "social imaginary," but the possibility of being in one could not exist without a more general and shared sense of potentially or actually belonging to the public. Like Taylor, Warner distinguishes between the possibility of a crowd, an assembly, a discussion (a topical public), and a public constituted through an imagined participation in a discussion (a meta-topical public).

However, Warner is careful to note the circularity implied in the process of a public coming into being. Publics require more than simply speech or writing, they require a more nuanced sense of the very act of being addressed. To be part of a particular public is to choose to pay attention to those who choose to address those who choose to pay attention ... and so on. Or as Warner puts it, "The circularity is 
essential to the phenomenon. A public might be real and efficacious, but its reality lies in just this reflexivity by which an addressable object is conjured into being in order to enable the very discourse that gives it existence" (2002a:51). That is to say, publics have no preexisting determinant that give them form other than the shared social imaginary (the background understanding) of being potentially addressable as a public. People are not always in the public, but they are always ready to be.

Silk List and similar forums can be understood as particular publics, and as I have tried to demonstrate, by detailing their shared concern for protocols, implementations, and the openness of the infrastructure in which they address each other and pay attention to each other, they are a recursive public - they address each other by addressing the very means (the Internet) of address itself. If, as Warner suggests, publics are constituted solely through the self-referential and selforganizing system of address, then the above example suggests that the particular sociotechnical constitution of the means of address may also be the proper subject of a public. Public discussion includes both speech-with all of its performative and rhetorical tools - at the same time that it involves the creation of software and networks, that is, the Internet conceived as a publicly accessible and open network.

In Warner's examples, publics address each other to make themselves heard on subjects ranging from sex to political representation to religion. In making this address, they push on the limits of what is "properly" public in some context or another-they question the rules of public discourse (e.g., shall gay men speak about sex in public?). Geeks are engaged in a similar activity, but the rules they push on are the technical protocols and standards that allow them to speak about anything at all (whether properly public in Warner's sense or not). For geeks, the "address" as such is what interests them first, not the particular content of an address, and so they turn to technical and legal activities that concern the conditions of possibility of address. To include the activities of building, coding, compiling, patching, hacking, redistributing, and sharing software code and networking tools under the banner of discourse is the first step toward understanding how the definition of a social imaginary is transformed by the Internet. I highlight again here the recognition among geeks that the possibility of address is produced, not given, and that it must therefore be actively maintained rather than simply employed-just as it is necessary to continue to speak about freedom to ensure freedom of speech. The fact that geeks refer to the inevitability of technical progress does not in any way signal a contradiction; rather, they are among the most seriously committed to the maintenance and production of the possibility of address that is the (current and open) Internet. Seen from within their social imaginary, the geeks' assertion that the particular structure of the Internet enables and enforces maximum openness is not an ontological claim about the way the Internet is, so much as it is a hermeneutic and prescriptive one that is focused on maintaining a particular moral order, or if it proves absent, a plan for achieving it. 
Taylor suggests that a social imaginary is not a theory but a set of stories and narratives that are indistinguishable from practice. However, he gives little sense of what these stories and practices do or what makes them meaningful. The folklore of the Internet - of sensing damage and routing around it, of a history of rough consensus and running code - are stories about the practices of creating code and protocols. However, this loose set of stories, images, reasons, or ideas of robustness, elegance, openness, and scalability are both discussed and implemented, and these implementations are then both critiqued and reimplemented. Although one might discuss at length the particular ways in which something ought to be implemented, for most geeks, the most important component of this discussion is the code itself, which geeks see as the final statement. The ability to bypass argument and simply point to a technology or a program that invalidates an interlocutor's point (and expresses a particular story) is the ultimate rhetorical power-particularly because it possesses the virtues of exactness and functionality that they often claim political speech lacks.

The notion of a social imaginary therefore needs some rethinking in the era of technoscientific globally networked societies. First of all, the social, as far as geeks are concerned, includes the relations among flesh-and-blood blobs of protoplasm interacting face-to-face (or face-to-screen) as well as the relations between different forms of software, hardware, networking protocols, and legal or regulatory regimes interacting in abstruse but generally precise technical ways. That is to say, geeks share an imagination of what society or sociality is: it includes the technically mediated software and networks that undergird our connectedness as much as it does any classic formulation of family, kin, nation, or corporate connection.

Second, the imaginary also takes on a new cast amongst geeks: software and networks tend to render shared imaginaries that are not only concrete but also flexible in ways that other practices do not. For instance, the creation of a corporation, based on a shared imaginary of the economy (or of how markets are supposed to work), is the creation of a concrete set of relations and practices; it is one that is generally inflexible - even in this age of so-called flexible capitalism-because it requires a commitment of time, humans, and capital. Software and networks, on the other hand, can be equally concrete-connecting people, capital, and other resources over time and creating an infrastructure-but they are arguably more flexible, more changeable, and reprogrammable - than a corporation, a sewage system, or a stock exchange. There is therefore more room for argument and implementation in the particular imaginary at work. A recursive public can not only propose changes that should be made in the future (as an employee in a corporation might) but actually make those changes to the software and let others test whether the change is fruitful. However, just as one can convincingly argue for an alternative world in speech or writing without making it come true, so can one actually create an alternative to current networks or software without anyone (or very many people) actually using it. The social imaginary references the freedom to imagine another world — whether in speech or in code-but it also implies the 
need to get other people to share this imaginary and to make it the basis of political action. The means for and difficulties of enrolling others are as many and diverse as they are for any public, but in this case, the actual creation of "running code" is a better argument than a proposal to create running code-consensus comes as more people begin to use that code.

In the world of software and networks, however, the leap from imagining an alternative to instantiating that alternative can be radically reduced. Software is actually doing, whereas talking is merely talking: "shut up and show me the code." Another way of saying this is that geeks share an imaginary of how to conduct reasoned deliberation not just about but through the creation of technical objects. Of all the possible software and networks that might be discussed and implemented in this fashion, for the last quarter century it has been the Internet that geeks have been most concerned to protect and to keep as radically open as possible-for it is now the sine qua non of any other software or network they or anyone else might build.

Contrast this with a nonrecursive public such as a newspaper or a political gathering. People who write in newspapers or who organize rallies occasionally consider it necessary to argue about the technology (or ownership structure) of the newspaper or the architecture of a stadium that permits them to address a public in the first place. Similarly, some readers of a newspaper or attendees may consider the fact that some structural features of these public forums for discourse subvert the possibility of creating a public in the first place: blind readers must find ways around print and the wheelchair-bound around stairs. However, neither newspapers nor their readers consider it even remotely possible that the public discussion they facilitate (the newspaper itself) should be open to transformation or reformulation directly by that public. They may well respond to a public that makes an issue of the structure of a newspaper or its particular format, content, or distribution. Similarly, stadium owners can be forced by courts to transform their access routes to comply with the law. The difference is that these organizations "possess" power in this strict sense of the right to decide. The Internet, as it exists today, is not structured this way. No single entity or group can prevent the system from being changed from within. Publics troubled by the current state of newspaper-or more specifically, troubled by the existing technical tools for printing and distributing newspapers - often have little recourse other than to start a new newspaper, or in the most extreme case, to recreate the printing and distribution system from scratch.

So far, the Internet has been different in precisely this respect: its peculiar technical structure as a medium and a network has, in fact, been historically open to the creation of alternatives - even if no one uses or needs those alternatives (e.g., by now thousands of different file-sharing programs are available, but only some of them are in widespread use the way Napster was). Above all, geeks recognize how powerful-and how fragile-this feature of the Internet is, and they very much wish to maintain it. It is not a position opposed to legitimate governance, it 
is a social imaginary that justifies the legitimate authority of technical and legal openness.

\section{Conclusion}

Charles Taylor argues that what made the social imaginary of the public sphere so powerful and successful in the 18th century was its status as: "a space of discussion that is self-consciously seen as being outside of power. It is supposed to be listened to by power, but it is not itself an exercise of power ... because public opinion is not an exercise of power, it can be ideally rational and disengaged from partisan spirit" (2004:89-90). As Habermas (1989) described them, the practices that make up this extrapolitical space were not instituted by any legislative or political maneuver of a government or church but came about through the particular material and media formations of bourgeois society in 18th-century Europe (e.g., the circulation of newspapers, pamphlets, and letters; the new popularity of coffeehouses and salons; the rise of the novel; the distinction of the public from the intimate) that gave the abstract notion of public opinion a kind of materiality. Similarly, Michael Warner argues that it is self-organization through discourse that gives a public its power:

A public organizes itself independently of state institutions, law, formal frameworks of citizenship, or preexisting institutions such as the church. If it were not possible to think of the public as organized independently of the state or other frameworks, the public could not be sovereign with respect to the state... Speaking, writing, and thinking involve us - actively and immediately — in a public, and thus in the being of the sovereign. [Warner 2002a:51-52]

In the 21 st century, in which e-mail, chatrooms, instant messaging, independent media, blogs, Google, mobile phones, pagers, Friendster, and other media are also concrete means of discussion, argument, and assertion, we can broaden the notion of Tischgesellschaft (coffeehouse society) to that of a far-flung, technically mediated, and dynamically networked Schreibtischgesellschaft (desktop society). The activities of geeks suggest that we should extend our conception of the public from the activities of "speaking, writing, and thinking," which have defined it classically, to include building, coding, compiling, patching, hacking, redistributing, and sharing.

Rather than simply regaling ourselves with stories of the evolution of technology (from ostensive gesture to grunt to papyrus to print to cyberspace), the notion of a recursive public asks us to see the development of these tools inversely-as meaningful precisely because of the stories we tell about them and the ways in which we seek to implement them. Rather than treat the Internet as one of a long string of technologies that either constrain or liberate the voices of humans who seek to affirm or deny old values, the recursive public treats the Internet as a contest, the outcome of which will structure the very meaning and instantiation of both old and new values. 
The Internet has possessed (to date) a historically contingent form of technical and social openness; through this particular material means, publics are brought into existence. Now, this historical fact is also the subject of public discussion-a recursive one-that includes the technical attempts to maintain it or transform it. This means that it matters who controls the technical means of discourse; more specifically, it matters who builds it, how it is built, and whether speaking about it or rebuilding it is open to anyone.

Censorship, propaganda, and intimidation are old and familiar forms of control or repression by governments or churches. In these cases, the sovereign public faces an illegitimate sovereign directly, sometimes violently. But the concept of a recursive public suggests that we ask what kind of relationship exists when governments, corporations, and other institutions provide people with a means to speak, write, or think with each other (such as when a government provides a telephone and telegraph system or a corporation creates and runs a mobile-phone network). Does the shape and governance of the means of discourse also shape the discourse itself? What does it mean for any organization (whether public or private, corporate or state, or secular or religious) large enough to create and define effectively the character and possibility of address? After all, someone has to- not all communications media are natural human capacities, and in the 21 st century almost none are state owned or even very strictly regulated by states. The Internet, telecommunications devices, radio spectrum, mobile phones, instant messaging, Internet service providers (ISPs), computer hardware, software and networks, and so on, are all tools through which these self-organizing publics constantly come into being. All of these tools both limit and produce new possibilities for how individuals can address each other and sustain arguments among themselves-but how many of them allow for a recursive investigation of the architectures and legal practices by which they do so? As I have learned from geeks, structures of communication are not inevitable, given, or neutral; for any public to become a sovereign entity in contemporary technical societies, it must be recursive.

Although the social imaginary of a recursive public might sound suspiciously vicious and irrelevantly technical to some, it has, in fact, forked into other realms and other matters of concern. In the last six years alone, especially in the wake of the explosion of free and open-source software, recursive publics have found new constituencies-musicians, scientists, educators, filmmakers, collectors, activists, and architects. All of these groups have adopted not just the rhetoric of openness but also a particular attitude toward the conditions of possibility of openness - and the modes of manipulating them technically and legally - on and off the Internet. ${ }^{28}$ Most of these groups see themselves as expressing universal concerns-especially when the technical issue is the very possibility of "expressing a concern" at alland this may well mean they are subject to the same critiques of liberal ideals of universalism familiar in anthropology (Coombe and Herman 2004). Nonetheless, the transformation of other kinds of technical and legal architectures (not just the Internet) by individuals committed to similar kinds of social imaginaries as those 
described here may very well become a much more common feature of political life.

Of course, not all people who are concerned with the Internet share this social imaginary. The idea that the core protocols of the Internet should be open for anyone to change (or that legal rules can be trumped by private ordering) is radical and selfconsciously so. It even takes on different forms of radicalism: libertarian objections to regulation, anarchist visions of gyroscopic governance, technocratic proposals, as well as more classical liberal political claims for free speech, assembly, and press. ${ }^{29}$ It is also true that only some people possess the requisite technical knowhow or passion that allows them to join this (recursive) discussion. Argument-bytechnology is not for everyone, and this article has focused on one very particular mode and moment of its action to explain how it works. However, for being arcane, geeks are no less a public_resolutely self-organized, independent of state, corporation, or church. The specificity of this recursive public's engagement with the Internet allows outside observers to see not just how people relate "on" the Internet but that the Internet itself is, at any given moment in time, a process of political contest.

\section{Notes}

Acknowledgments. This article has seen many drafts as well as assistance from many people. At various stages, I have been grateful for comments from Michael Fischer, Joseph Dumit, Gabriella Coleman, Jenny Cool, James Faubion, George Marcus, Stephen Collier, Adriana Petryna, Michael Mahoney, Angela Creager and the Workshop in the History of Science at Princeton, Thomas Chivens, and, throughout the process, Hannah Landecker. I would also like to acknowledge the encouragement of Ann Anagnost, and the comments of the five anonymous reviewers of this article. Support for this research was provided by the National Science Foundation and the Social Science Research Council.

1. This choice of shorthand is meant to be as inclusive as possible. Geek is a term used both by myself and by my informants. Although the term geek indicates a fondness for, and curiosity about, technology (especially digital technology), it does not imply that this is their primary identification. I have met businessmen, lawyers, activists, bloggers, gastroenterologists, anthropologists, lesbians, schizophrenics, scientists, poets, people suffering from malaria, sea captains, drug dealers, and people who keep lemurs-all of whom refer to themselves as geeks. Moreover, I include myself within this category. The term geek shares an affinity with hackers, although the former is often used to evoke a chuckle rather than to describe those engaged in criminal activity (Levy 1984; Thomas 2002; Turkle 1984). The general tendency of much mass media and academic writing is to lump together hackers, geeks, cyberpunks, and other subcultural categories of computer users (see Coleman and Golub n.d. for an exception), a tendency I follow insofar as all of these different groups share a background that structures the social imaginary that I am trying to articulate here. These labels are less important in this article than my designation of this group as a "recursive public," by which I mean a group of individuals who, more often than not, only associate with each other because of a shared concern for the conditions of possibility of their own association (i.e., the Internet).

2. On social imaginaries, I rely in particular on two authors: Charles Taylor (2002, 2004) and Michael Warner (2002a; 2002b). The social imaginary concept seems to have 
a gloriously promiscuous paternity, even within the special issue cited above. Taylor cites Benedict Anderson (1991) as the source of the notion, although others refer to it as Taylor's own. Castoriadis is frequently referenced, but he disavows most any use of it but his own (Castoriadis, 1987:3), which is partially derived from the Lacanian psychoanalytic triad Real-Imaginary-Symbolic and processed through Althusserian Marxist currents of mid20th century France. The clearest presentation is given by Taylor (2004:23ff.). Taylor's terminology and theory avowedly rely exclusively on Western European theorizations of social imaginaries and moral orders. Another terminology that might be usefully contrasted with "social imaginary"- and one that certainly dispenses with the overarching Western focus in Taylor-is that of "regimes of living" in (Collier and Lakoff 2004). In this work, "regimes of living" are explored cross-culturally and in terms of various modernities across the globe. The question of whether the Internet is a "public sphere" has been variously addressed: in positive terms (Saco 2002; Yang 2003), critiqued (Dean 2003; Dreyfus 2001), and rendered incoherent (Rodman 2003).

3. Although they are an essential component of what is described here, I will not dwell at length on the history or meaning of Free Software and Open Source software, which is arguably the paradigm case of contemporary privately ordered legal regimes. A "privately ordered legal regime" is a term from law and economics that refers to systems of economic governance neither instituted nor overseen by existing governments (i.e., they are instead overseen by private citizens). Free and Open source software is such a regime because, in the course of their normal functioning, they rely on the circulation, trading, and private adjudication of copyright licenses between individuals and sometimes between firms and not solely on existing federal or state intellectual property law. There is a significant body of legal scholarship in law and economics that treats other forms of private ordering as a more general phenomenon-some of it surprisingly detailed ethnographically (Bernstein 1992; Ellickson 1991). See also Kelty 2004b.

4. The definition of "recursive" employed here is the mathematical or logical one, which is a standard feature of any education in computer programming. The definition from the Oxford English Dictionary: "2. a. Involving or being a repeated procedure such that the required result at each step except the last is given in terms of the result(s) of the next step, until after a finite number of steps a terminus is reached with an outright evaluation of the result." In the usage employed in this article, a recursive public is one whose existence (which consists solely in address through discourse) is only possible through discursive and technical reference to the means of creating this public. Recursiveness is always contingent on a limit that determines the depth of a recursive procedure-similarly, the depth of discussions about recursive public often ends at the physical limits of communication media or the political limits of infrastructure provision.

5 . There is by now a very wide range of research that might be lumped together under the heading of "anthropology of the Internet" but probably evokes instead the famed Chinese encyclopedia of Borges: overviews and general monographs (Escobar 1994; Fischer 1999; Hakken 1999; Miller and Slater 2000; Wilson and Peterson 2002); studies of particular on-line communities (Hine 2000; Ito et al. 2001; Lysloff 2003; Slater 2002); critiques of "site" and of "virtuality" (Helmreich 2003; Ito 1996; Marcus 1996; Miller and Slater 2000; Woolgar 2002); archaeological studies of high technology (Finn 2001); studies of "chat" (Cherny 1999); calls for an "institutional" treatment of the Internet (Agre 1998; Mansell 2002); mermaids and pirates (Ludlow 2001); ethnographies that have nothing to do with the Internet but make use of it as a source or site in medical and biomedical anthropology (Franklin and Locke 2003; Novas and Rose 2000; Rapp et al. 2001) and in studies of social movements (Cleaver 1998; Ronfeldt and Arquilla 1998; Zaloom 2003); provocative and wide-ranging books that tremble as if they were mad (Lovink 2002); innumerable 
geographical and political economic analyses (Bimber 2003; Crampton 2003; Everard 2000; Mosco 2004; Saco 2002); fabulous ones (Berry et al. 2003; Gottlieb and McLelland 2003); and studies that look like Kierkegaard from a great distance (Dreyfus 2001).

6. This approach extends the work in science and technology studies (Callon 1986; Latour 1987, 1999b; Law 1999) and more recent interests at the interface of science studies and economic sociology (Callon 1998).

7. It is all too easy to dismiss geeks as libertarians blinded by a belief in technical progress and unsympathetic to any kind of public interest (e.g., Borsook 2000), however, calling something libertarian is neither an analysis nor a grounds for critique. What follows in this article is intended to detail the ways in which geeks - whether libertarian or not-argue about, and try to maintain, a particular social order that has a certain kind of public interest at its heart.

8. For this issue among the League of Women Voters, see the story in USA Today (Konrad 2004). For more information and references on this point, see http://www. verifiedvoting.org.

9. Shortly after arriving, one of these contacts pointed out an article in Wired to me. The author describes being at the same pub and having much the same experience, although no doubt being paid considerably more to do so (Wetzler 2000: 4). The author, whose cultural barometer was no doubt more finely wrought than mine, mentions only that Led Zeppelin was playing while he was there and mentions nothing further on the subject of heavy metal (Wetzler 2000: 4).

10. Body shopping is a term specifically used in the context of software, engineering, and data entry, and is often used by these informants when speaking of themselves. Its meaning is equivalent to "head hunting" in other professional spheres.

11. At the time, this was an absurdly high number, an overestimation of India's potentially mobile IT workforce, caused, no doubt, in part by India's own marketing of the industry that has grown from a negligible amount to an impressive 3 percent of GDP in 2002-03.

12. Several reviewers of this article in its various stages have raised the question of the gender of geeks. It is true that they are overwhelmingly male, although by no means exclusively or happily. This discrepancy is noted repeatedly by geeks themselves and certainly lamented more often by geeks than by cultural anthropologists. The gendering of hackers and geeks and the more general exclusion of women in computing has been widely observed by academics (Light 1999; Turkle 1984, 1995). Given the putative liberating possibilities of cyberspace (Stone 1995), the replication of familiar gendered modes of discourse on-line merits careful attention. The gender question in this case is similar to the case of queer politics articulated so well by Michael Warner, among others, and raises two separate issues: (1) why are there not more women (queers, African Americans, Latinos, and others) who tinker? (2) what difference does gender (or identity more broadly) make to the concept of recursive publics? To answer the first question, there are some women who do, as evidenced by organizations such as LinuxChix.org or Womengamers.com (and the number seems to be growing). Computer science departments at universities such as my own cite the lack of women in their discipline as a pressing problem and have instituted programs such as all-female computer summer schools for high school girls. Whether this will alter the social landscape of geeks is difficult to say. However, the presence or absence of women (or of people, in general) who do not tinker does not address the second question. To build on Warner's argument, I would suggest that technical elites are generating counterpublics within their own ranks, and these individuals are participating in critical forms of practice vis-à-vis another much larger and dominant technology industry that has a tendency to treat them as inappropriate, dangerous, and/or subversive. 
13. The last ten years have yielded a number of new names (and new denunciations) for elites of various kinds who are associated with digital technology: the "digerati," the "California Ideology" (Barbrook and Cameron 1996), as well as a number of both pre- and postbubble critiques (Borsook 2000; Brooks and Boal 1995; Lovink 2002; Winner 1995). There are also, of course, both critical and hagiographic popular accounts and biographies too numerous to list.

14. I would not suggest that such an ethnography is impossible. Several ethnographies that deal with similar issues and problems of characterization are in process, including work by Gabriella Coleman, Jenny Cool, and Anita Chan. See also the collection of short pieces in Kelty 2004a.

15. The rest of this message can be found in the Silk List archives at http://groups. yahoo.com/group/silk-list/message/2869 (last accessed December 1, 2003). The reference to "Fling" is to a project now available at http://fling.sourceforge.net (last accessed January 5, 2005). I have chosen this message more or less randomly, but it is, in my opinion, a very representative example of the points I am making here. Several others like it circulated during the summer of Napster. The full archives of Silk List can be found at http://groups.yahoo.com/group/silk-list and the full archives of the FoRK list can be found at http://www.xent.com/mailman/listinfo/fork.

16. This was true also in the case of Metallica, who famously came out in opposition to all forms of music sharing without remuneration and briefly became the darlings of the RIAA.

17. Transhumanists and extropians are loosely affiliated groups of scientifically minded individuals committed to a set of goals that include immortality, artificial intelligence, space travel, and nanotechnology. The most salient binding ideology is the belief in the inevitable and autonomous progress of technology. See the World Transhumanist Association (WTA) site, http://transhumanism.org (last accessed December 1, 2003) or the Extropy Institute's site, http://www.extropy.org (last accessed December 1, 2003). See also (Doyle 2003) for a sidelong glance. Moore's law and Metcalfe's law are frequently cited by engineers and technologists. Moore's law, named for Gordon Moore, former head of Intel, states that the speed and capacity of computer CPUs doubles every 18 months, which it has done since roughly 1970. Metcalfe's law is named for Robert Metcalfe, inventor of Ethernet, and states that the utility of a network equals the square of the number of users or that the number of things one can do with a network increases exponentially as members are added linearly.

18. It is also perhaps worth mentioning that the long drawn out set of flame wars about Napster that summer included a lot of moralizing about morals - that is to say, the list was fairly evenly split between those who believed "just because you can, doesn't mean you should" and those who believed that "what you should do is contingent on what you can." These two sides contained extreme versions (from "stealing is wrong" on one side to "technology is inevitable" on the other), as well as centrist versions that emphasized the importance of pragmatic solutions, such as developing new "business plans" in the recording industry.

19. Whether there is any truth to this widespread belief is not clear. On the one hand, the protocol to which this folklore refers - the general system of "message switching" and later "packet switching" invented by Paul Baran at RAND-does seem to lend itself to robustness (on this history, see Abbate 1999). On the other hand, it is not clear that nuclear threats were the only reason for such robustness-simply ensuring communication in a distributed network was a laudable goal in itself. Nonetheless, the story has great currency as a myth of the nature and structure of the Internet.

20. Over the last ten years, several of these have been in transformation. The Internet Corporation for Assigned Names and Numbers (ICANN), the Internet Society, the World 
Wide Web Consortium (W3C), and the Internet Engineering Task Force (IETF) have been the most visible and contested ones.

21. This is constantly repeated on the Internet and attributed to David Clark, but no one really knows where or when. It appears in a 1997 interview of David Clark by Jonathan Zittrain, The transcript is available at: http://cyber.law.harvard.edu/jzfallsem//trans/clark (last accessed January 5, 2005).

22. A very good explanation of Internet protocols and their function is provided in Galloway 2004.

23. Ashish "Hash" Gulhati, e-mail to Silk List mailing list, September 9, 2000, http://groups.yahoo.com/group/silk-list/message/3125.

24. Eugen Leitl, e-mail to Silk List mailing list, September 9, 2000, http://groups. yahoo.com/group/silk-list/message/3127.

25. In particular, this project focuses on the Transmission Control Protocol (TCP), the User Datagram Protocol (UDP), and the Domain Name System (DNS). The first two govern how small chunks of data will be divided and routed in an orderly fashion from machine to machine, the third governs what machines will be linked to which names (e.g., my server is at http://smatter.rice.edu or 128.42.98.21). For a technical protocol, the DNS has generated a surprising amount of attention, political strategy, economic anxiety, and protest. For the history of this turmoil, see Mueller 2002.

26. Fling, as a project, may or may not be successful and may, in fact, be totally forgotten. Bone's point is that regardless of the specific outcome, there will always be others who will attempt to achieve the same goals.

27. See RFCs 821 and 2821, Simple Mail Transfer Protocol, http://www.rfc-editor.org.

28. Among the most well-known are Creative Commons (http://www. creativecommons.org), the Public Library of Science (http://www.plos.org), Open Courseware at MIT (http://ocw.mit.edu), and the Connexions project at Rice University (http://cnx.rice.edu).

29. It is important to note that this vision of openness has been under attack from various quarters, for at least as long as the Internet has been in the public eye (starting roughly, perhaps ironically, in 1989). Sovereign entities such as the United States Congress, and the European Parliament (and the groups who lobby them) have sought to legislate that the Internet take one form or another; similarly, large corporations also see the Internet as a contestable and changing thing but would prefer it to be their contestable and changing object. There has been extensive debate about the new and highly complex legislation regarding the Internet, telecommunications regulation, and intellectual property such as the Telecommunications Act of 1996, Pub. LA. No. 104-104, 110 Stat. 56 (1996) and the Digital Millennium Copyright Act, HR 2281, Report 105-796. This kind of regulation extends from censorship (antiobscenity law) to communications regulation (and extensions of antitrust law), copyright law, and laws governing privacy and the possession and use of cryptography.

\section{References Cited}

Abbate, Janet

1999 Inventing the Internet. Cambridge, MA: MIT Press.

Agre, Phil

1998 Yesterday's Tomorrow. Times Literary Supplement, July 3:3-4.

Anderson, Benedict R. O. G.

1991 Imagined Communities: Reflections on the Origin and Spread of Nationalism.

New York: Routledge.

Barbrook, Richard, and Andrew Cameron

1996 The California Ideology. Science as Culture 26(6):44-72. 
Barlow, John Perry

1994 The Economy of Ideas. Wired Magazine 2.03, March 1993. Electronic document, http://www.wired.com/wired/archive/2.03/economy.ideas_pr.html, accessed January 6, 2005.

Bernstein, Lisa

1992 Opting out of the Legal System: Extralegal Contractual Relations in the Diamond Industry. Journal of Legal Studies 21:115-157.

Berry, Chris, Fran Martin, and Audrey Yue, eds. 2003 Mobile Cultures: New Media in Queer Asia. Durham, NC: Duke University Press. Bimber, Bruce A.

2003 Information and American Democracy: Technology in the Evolution of Political Power. Cambridge: Cambridge University Press.

Borsook, Paulina 2000 Cyberselfish: a Critical Romp through the Terribly Libertarian Culture of High Tech. New York: Public Affairs.

Brooks, James, and Iain A. Boal, eds.

1995 Resisting the Virtual Life: The Culture and Politics of Information. San Francisco: City Lights.

Callon, Michel

1986 Some Elements of a Sociology of Translation: Domestication of the Scallops and the Fishermen of St-Brieuc Bay. In Power, Action and Belief: A New Sociology of Knowledge? John Law, ed. Pp. 196-233. London: Routledge.

Callon, Michel. ed.

1998 The Laws of the Markets. Oxford: Blackwell.

Castoriadis, Cornelius

1987 The Imaginary Institution of Society, Cambridge, MA: MIT Press.

Cherny, Lynn

1999 Conversation and Community: Chat in a Virtual World. Stanford: CSLI Publications.

Cleaver, Harry

1998 The Zapatista Effect: The Internet and the Rise of an Alternative Political Fabric. Journal of International Affairs 51(2):621-640.

Coleman, Gabriella, and Alex Golub

N. d. Toward a Theory of Hacker Ethical Practice. Unpublished MS, Department of Anthropology, University of Chicago (on file with author).

Collier, Stephen, and Andrew Lakoff

2004 Regimes of Living. In Global Assemblages: Technology, Politics, and Ethics as Anthropological Problems. Aihwa Ong and Stephen J. Collier, eds. Pp. 22-49. Malden, MA: Blackwell.

Coombe, Rosemary, and Andrew Herman

2004 Rhetorical Virtues: Property, Speech and the Commons on the World-Wide Web. Anthropological Quarterly 77(3):559-574. Electronic document, http://aq.gwu. edu/ gwaq, accessed February 14, 2005.

Crampton, Jeremy

2003 The Political Mapping of Cyberspace. Chicago: University of Chicago Press.

Dean, Jodi

2003 Why the Internet is not a Public Sphere. Constellations 10(1):95-111.

Doyle, Richard

2003 Wetwares: Experiments in Post-Vital Living. Minneapolis: University of Minnesota Press. 
Dreyfus, Hubert

2001 On the Internet. London: Routledge.

Ellickson, Robert C.

1991 Order without Law: How Neighbors Settle Disputes. Cambridge, MA: Harvard

University Press.

Escobar, Arturo

1994 Welcome to Cyberia: Notes on the Anthropology of Cyberculture. Current Anthropology 35(3):211-231.

Everard, Jerry

2000 Virtual States: The Internet and the Boundaries of the Nation-State. London:

Routledge.

Finn, Christine

2001 Artifacts: An Archaeologist's Year in Silicon Valley. Cambridge, MA: MIT Press.

Fischer, Michael M. J.

1999 Worlding Cyberspace: Toward a Critical Ethnography in Time, Space, and The-

ory. In Critical Anthropology Now: Unexpected Contexts, Shifting Constituencies,

Changing Agendas. G. Marcus, ed. Pp. 245-304. Santa Fe, NM: SAR Press.

Franklin, Sarah, and Margaret Lock, eds.

2003 Remaking Life and Death: Towards an Anthropology of the Biosciences. Santa Fe, NM: SAR Press.

Galloway, Alex

2004 Protocol, or How Control Exists after Decentralization. Cambridge, MA: MIT Press.

Gottlieb, Nanette, and Mark McLelland, eds.

2003 Japanese Cybercultures. London: Routledge.

Habermas, Jürgen

1989 The Structural Transformation of the Public Sphere: An Inquiry into a Category

of Bourgeois Society. Cambridge, MA: MIT Press.

Hakken, David

1999 Cyborgs@Cyberspace?: An Anthropologist Looks to the Future. New York:

Routledge.

Helmreich, Stefan

2003 Spatializing Technoscience. Reviews in Anthropology 32(1):13-36.

Hine, Christine

2000 Virtual Ethnography. Thousand Oaks, CA: Sage.

Ito, Mizuko

1996 Theory, Method and Design in Anthropologies of the Internet. Social Science Computer Review 14(1):24-26.

Ito, Mizuko, with Vicki O'Day, Annet Adler, Charlotte Linde, and Elizabeth Mynatt 2001 Making a Place for Seniors On the Net: SeniorNet, Senior Identity, and the Digital Divide. Computers and Society 31(3):15-21.

Kelty, Christopher

1999 Scale and Convention: Regulated Languages in a Programmed America, Ph.D. dissertation, Program in Science, Technology and Society, MIT.

2004a Culture's Open Sources. Anthropological Quarterly 77(3):499-506. Electronic document, http://aq.gwu.edu/ gwaq, accessed February 14, 2005.

2004b Punt to Culture. Anthropological Quarterly, 77(3):547-558. Electronic document, http://aq.gwu.edu/ gwaq, accessed February 14, 2005.

Konrad, Rachel

2004 Fight over Electronic Voting Riles League of Women Voters. USA Today, June 
6. Electronic document, http://www.usatoday.com/tech/news/techpolicy/2004-06-10evote-league_x.htm, accessed June 24, 2004.

Latour, Bruno

1987 Science in Action: How to Follow Scientists and Engineers through Society. Philadelphia: Open University Press.

1999a On Recalling ANT. In Actor Network Theory and After. John Law and John Hassard, eds. Pp. 15-25. Oxford: Blackwell.

1999b Pandora's Hope: Essays on the Reality of Science. Cambridge, MA: Harvard University Press.

Law, John

1999 Actor-Network Theory and After. Oxford: Blackwell.

2002 Aircraft Stories: Decentering the Object in Technoscience. Durham, NC: Duke University Press.

Lessig, Lawrence

1999 Code: And Other Laws of Cyberspace. New York: Basic Books

Levy, Steven

1984 Hackers: Heroes of the Computer Revolution. New York: Dell.

Light, Jennifer S.

1999 When Computers Were Women. Technology and Culture 40(3):455-483.

Lovink, Geert

2002 Dark Fiber: Tracking Critical Internet Culture. Cambridge, MA: MIT Press.

Ludlow, Peter, ed.

2001 Crypto Anarchy, Cyberstates, and Pirate Utopias. Cambridge, MA: MIT Press.

Lysloff, René T. A.

2003 Musical Community on the Internet: An Online Ethnography. Cultural Anthropology 18(2):233-263.

Mansell, Robin, ed.

2002 Inside the Communication Revolution: Evolving Patterns of Social and Technical

Interaction. Oxford: Oxford University Press.

Marcus, George E., ed.

1996 Connected: Engagements with Media. Chicago: University of Chicago Press.

Miller, Daniel, and Don Slater

2000 The Internet: An Ethnographic Approach. Oxford: Berg.

Mosco, Vincent

2004 The Digital Sublime: Myth, Power, and Cyberspace. Cambridge, MA: MIT Press.

Mueller, Milton

2002 Ruling the Root: Internet Governance and the Taming of Cyberspace. Cambridge, MA: MIT Press.

Novas, Carlos, and Nikolas Rose

2000 Genetic Risk and the Birth of the Somatic Individual. Economy and Society 29(4):485-513.

Rapp, Rayna, Deborah Heath, and Karen Sue-Taussig

2001 Genealogical Dis-Ease: Where Hereditary Abnormality, Biomedical Explanation, and Family Responsibility Meet. In Relative Values: Reconfiguring Kinship Studies. Sarah Franklin and Susan McKinnon, eds. Pp. 384-412. Durham, NC: Duke University Press.

Rodman, Gilbert B.

2003 The Net Effect: The Public's Fear and the Public Sphere. In Virtual Publics. Beth

E. Kolko, ed. Pp. 9-48. New York: Columbia University Press.

Ronfeldt, David, and John Arquilla

1998 The Zapatista "Social Netwar" in Mexico. Santa Barbara, CA: RAND 
Publications. Electronic document, http://www.rand.org/publications/MR/MR994/, accessed January 6, 2005.

Saco, Diane

2002 Cybering Democracy: Public Space and the Internet. Minneapolis: University of Minnesota Press.

Schmidt, Susanne K., and Raymund Werle

1998 Coordinating Technology: Studies in the International Standardization of Telecommunications. Cambridge, MA: MIT Press.

Slater, Don

2002 Making Things Real: Ethics and Order on the Internet. Theory, Culture and Society 19(5-6):227-246.

Stone, Allucquere Rosanne

1995 The War of Desire and Technology at the Close of the Mechanical Age. Cambridge, MA: MIT Press.

Taylor, Charles

2002 Modern Social Imaginaries. Public Culture 14(1):91-124.

2004 Modern Social Imaginaries. Durham, NC: Duke University Press.

Thomas, Douglas

2002 Hacker Culture. Minneapolis: University of Minnesota Press.

Turkle, Sherry

1984 The Second Self: Computers and the Human Spirit. New York: Simon and Schuster.

1995 Life on the Screen: Identity in the Age of the Internet. New York: Simon and Schuster.

Vinge, Vernor

1993 The Coming Technological Singularity: How to Survive in the Post-Human Era.

Electronic document, http://www.rohan.sdsu.edu/faculty/vinge/misc/singularity.html, accessed December 1, 2003.

Warner, Michael

1990 The Letters of the Republic: Publication and the Public Sphere in EighteenthCentury America. Cambridge, MA: Harvard University Press.

2002a Publics and Counterpublics. Public Culture 14(1): 49-90.

2002b Publics and Counterpublics. New York: Zone Books.

Wetzler, Brad

2000 Boomgalore. Wired 8.03: 1-7. Electronic document, http://www.wired.com/ wired/archive/8.03/bangalore.html, accessed January 6, 2005.

Wilson, Samuel, and Leighton Peterson

2002 Anthropology of Online Communities. Annual Review of Anthropology 31:449467.

Winner, Langdon

1995 Peter Pan in Cyberspace. Educom Review 30(3):18-20.

Woolgar, Steve, ed.

2002 Virtual society?: Technology, Cyberbole, Reality. Oxford: Oxford University Press.

Yang, Guobin

2003 The Internet and the Rise of a Transnational Chinese Cultural Sphere. Media,

Culture and Society 25(4):469-490.

Zaloom, Caitlin

2003 Ambiguous Numbers: Trading Technologies and Interpretation in Financial Markets. American Ethnologist 30(2):258-272. 
ABSTRACT This article investigates the social, technical, and legal affiliations among "geeks" (hackers, lawyers, activists, and IT entrepreneurs) on the Internet. The mode of association specific to this group is that of a "recursive public sphere" constituted by a shared imaginary of the technical and legal conditions of possibility for their own association. On the basis of fieldwork conducted in the United States, Europe, and India, I argue that geeks imagine their social existence and relations as much through technical practices (hacking, networking, and code writing) as through discursive argument (rights, identities, and relations). In addition, they consider a "right to tinker" a form of free speech that takes the form of creating, implementing, modifying, or using specific kinds of software (especially Free Software) rather than verbal discourse. [Internet, public sphere, hackers, technology, software, intellectual property] 